\title{
A Participação das Mulheres na Luta de Libertação Nacional de Moçambique em Notícias (REVISTA TEMPO 1975-1985)
}

\author{
Jacimara Soura Santana ${ }^{1}$
}

\begin{abstract}
Resumo: Em Moçambique, como em outras partes da África, o jugo imposto às populações através da colonização européia atuou como uma das causas primordiais para o desencadeamento dos movimentos de descolonização e independência. Este artigo trata da participação que mulheres da zona rural e urbana tiveram no movimento de libertação nacional desse país, bem como alguns de seus impactos, a partir das entrevistas com ex-combatentes realizadas pela revista Tempo.
\end{abstract}

Palavras-chaves: África; mulheres; nacionalismo; emancipação; socialismo

Abstract: In Mozambique, as in other parts of Africa, the yoke tax to the populations through the European settling acted as one of the primordial causes for the unchaining of the movements of decolonization and independence. This article deals with the participation that women of the agricultural and urban zone had had in the movement of national release of this country, as well as some of its impacts, from the interviews with former-combatants carried through for the magazine Time.

Key-words: Africa; women; nationalism; emancipation; socialism

Moçambique é um país localizado na região Austral da África. Situa-se especificamente entre Tanzânia e África do Sul, fazendo fronteira ao oeste com Malauí, Zimbábue e Zâmbia e a leste, sua costa é banhada pelo Oceano Índico. Este território é dividido quase que ao meio por um dos maiores rios africanos, o Zambeze e a diversidade cultural também é uma marca de sua população. Trata-se de um território habitado por vários agrupamentos de povos ${ }^{2}$, Eduardo Homem e Sônia Correia indicaram um total de onze grupos, dos quais derivam trinta e uma línguas (CORREIA; HOMEM, 1977, P. 182) 3 .

A título de ilustração desta variedade, ao norte do país têm-se os Macuas e ao sul, os Tsongas. Estes primeiros habitam as Províncias de Niassa, Nampula, Cabo Delgado, uma parte da Zambézia e Tete, constituindo-se como um dos maiores agrupamentos populacionais da região setentrional do país. Enquanto que os Tsongas habitam as províncias da região sul: Maputo, Gaza e Inhambane. Moçambique ainda é marcado pela influência cultural dos árabes, cujo intercâmbio com os africanos deu origem a cultura

\footnotetext{
${ }^{1}$ Graduada em História; Especialista em Educação e Desigualdades Raciais e Mestra em História Social pela UFBA.

2 O termo povo aqui utilizado indica a variedades de agrupamentos de populações cuja língua, cultura e tradições são diferentes, mas habitam em um mesmo território. Optei não fazer uso do termo "etnia", conceito que ainda é bastante discutível apesar de aparece de forma predominante na bibliografia moçambicana consultada. Nas fontes, o termo que mais aparece é o de "tribo". Esse último foi utilizado pelos europeus para se referirem as diferentes sociedades africanas, de um modo geral. Trata-se de um termo carregado de uma conotação preconceituosa em relação às suas formas de vida e organização. Embora a Frelimo não comungasse com essa visão, continuou fazendo uso do termo para se referir aos povos do território moçambicano.
} 
suaíle, assim como dos indianos e portugueses, estes últimos responsáveis pela colonização deste país desde fins do século XIX ${ }^{4}$.

A luta armada não foi uma experiência vivida somente por Moçambique. Movimentos nacionalistas de outros países da África também utilizaram a guerra como meio de conquista de suas independências, a exemplo de Angola, Guiné Bissau, Cabo Verde e Zimbábue, inscrevendo-se em um processo amplo de lutas por descolonização nesse continente. Os Congressos Pan-Africanistas exerceram uma considerável influência na eclosão de movimentos de independência na África, dando lugar à formação da Organização da Unidade Africana (OUA) oficializada na Cúpula dos Estados Africanos entre 22 a 25 de maio de 1963, na cidade de Addis Abeba (Etiópia). Conforme Carlos Comitini essa organização possibilitou a convergência de diferentes e, até mesmo, de contraditórias tendências políticas existentes no continente africano para interesses comuns. (COMITINI, 1980, p. 18- 119):

Em princípio, a prioridade da OUA voltou-se para a gestão de políticas independentistas no continente. Em sua primeira conferência, esta Organização definiu uma série de resoluções em prol da descolonização e independência dos países africanos. Entre elas destacaram-se o rompimento das relações diplomáticas e econômicas dos Estados africanos com Portugal e um dos países desse continente, a África do Sul- em razão da resistência ao processo de descolonização e do regime de apartheid - bem como, a fundação de um Comitê Africano de Libertação com o objetivo de sustentar o processo de luta armada para a conquista da independência. Países socialistas, principalmente URSS, Cuba e China buscaram, da mesma forma, disponibilizar recursos para os movimentos nacionalistas, principalmente em Angola, Moçambique e Guiné Bissau, que após terem conquistado suas independências se assumiram como Estados socialistas e passaram a ter uma maior projeção nas Assembléias da OUA (MATEUS, 1999, p. 124).

\footnotetext{
4 A presença portuguesa em Moçambique data desde o século XVI, de início, na região denominado a partir de 1858 como Zambézia, compreendendo toda extensão territorial do centro do país que atualmente corresponde a quatro Províncias: Tetê, Sofala, Manica e Zambézia. Conforme José Capela durante três séculos, o domínio português foi mais nominal do que efetivo e foi sendo imposto ao longo desse período por meio de lutas contra a supremacia indiana e dos reinos locais, bem como, alianças e casamentos. $\mathrm{O}$ poderio português atingiu maior relevância a partir do século XVII quando prescindiu da tutela do governo indiano, mas é efetivamente a partir do século XIX que Portugal ampliou seu domínio nessa parte do continente africano, elegendo o seu primeiro governador geral. Antes disso, as povoações eram governadas por capitães e juízes mores eleitos pela pelas populações locais. Ainda parafraseando José Capela, a colonização portuguesa se efetiva de fato em fins do século XIX quando em termos administrativos Portugal veio a tornar-se hegemônico perante os reinos locais e ao domínio indiano. Para maiores informações consultar: CAPELA, José. Donas, Senhores e Escravos. Porto: Edições Afrontamento, 1995.
} 
Em Moçambique, como em outras partes da África, o jugo imposto às populações africanas através da colonização européia atuou como uma das causas primordiais para o desencadeamento dos movimentos de descolonização e independência. O domínio colonial de base capitalista, enraizado em conceitos de inferioridade racial sob forma de um discurso paternal se justificou como uma missão civilizadora para a África e impôs condições de vida degradantes às populações africanas. Em terras moçambicanas, a administração colonial introduziu a prática do trabalho assalariado obrigatório, denominado pelos africanos de chibalo ${ }^{5}$. Legalmente, o trabalho assalariado deveria ser um encargo masculino, por este motivo muitos homens se ausentavam por longos períodos de suas famílias, como é o caso daqueles que foram trabalhar nas minas da África do Sul (ZAMPARONI, 1998, P 13-30).

Apesar disso, mulheres também foram recrutadas para o trabalho nas roças particulares ou do Estado colonial, para abertura de estradas e trabalhos domésticos. Esta medida era arbitrária a lei colonial do trabalho e tinha como justificativa, a necessidade de pagamento das dívidas de seus parentes masculinos. Esta era a justificativa apresentada pela administração para o irregular recrutamento de mão-de-obra feminina, embora, muitas vezes, a acusação de dívidas fosse um caso mais de conveniência do que de situações reais, contudo houve casos de instituição de impostos para mulheres, denominado por Mudende. Conforme Valdemir Zamparoni, a partir de 1938, a administração colonial passou a exigir que a cobrança do imposto fosse per capita e desse modo, as mulheres entre 18 e 60 anos também deveria pagá-lo, o que gerou uma relevante sobrecarga de trabalho para os povos africanos, bem como favoreceu a prostituição. Na impossibilidade dos maridos e família em geral arcar com a dívida resultante dos impostos, mulheres poderiam ser vendidas ou prostituídas para prover a fonte de pagamento (ZAMPARONI, 1998, P 53-54).

Esta mesma divisão de gênero imbricada com questões raciais também se refletiu no sistema educacional. A escola era vista como uma exclusividade masculina, mas o acesso dos africanos ao ensino era difícil, visto que sua aquisição funcionava como um critério de distinção social. Os contemplados pelo sistema educacional pertencerem, geralmente, ao grupo da pequena burguesia africana que não estava exposta às mesmas condições que a maioria da população. Por volta de 1912, alguns líderes desta pequena burguesia haviam se pronunciado em relação à inclusão das mulheres nos estabelecimentos de ensino

\footnotetext{
${ }^{5}$ Para um maiores informações sobre o chibalo, consultar ZAMPARONI, Valdemir Donizette. Chibalo: trabalho livre, trabalho escravo? As discussões em torno do trabalho compulsório em Moçambique Colonial. In: COLÓQUIO INTERNACIONAL UNIVERSIDADE DE ÉVORA, 2001. Anais Porto: UNIVERSIDADE DE ÉVORA, 2001. P. $81-118$.
} 
(ZAMPARONI, 1998, p. 422-23; Tempo, jul. 1982, p. 14-17), embora o real interesse fosse o de torná-las melhores mães e esposas em correspondência com o modelo europeu de comportamento social. Foi nesse clima de contradição e negação do que podia ser definido como africano que emergiram as lutas anticolonialistas.

As iniciativas de resistência à colonização constituíram um verdadeiro subsídio ao movimento de independência. Bárbara Isaacman e June Stefhan identificaram iniciativas de mulheres - algumas de significativa relevância - como investidas anticolonialistas muito mais abrangentes no âmbito rural. A greve de Buzi, realizada em 1947, é um exemplo. Tratou-se de um movimento grevista que incluiu a participação de 7.000 mulheres que se recusaram ao cultivo do algodão, queimaram as sementes e participaram em outras ações contra as concessionárias algodoeiras, obtendo a isenção deste trabalho para as grávidas e mães com crianças de até 4 anos de idade. Outra iniciativa de fundamental importância foi a atuação das mulheres na propaganda de desprestígio do governo colonial perante a população e a divulgação de notícias do neófito movimento nacionalista, a Frente de Libertação Nacional de Moçambique, a Frelimo. (ISAACMAN; STEFHAN,1984, p. 23;MATEUS, 1999, p.59-60).

A Frente foi fundada em 25 de junho de 1962 e surgiu como resultado da "fusão" de outros três grupos nacionalistas organizados em países vizinhos de Moçambique: a UDENAMO (União Democrática Nacional de Moçambique) formada em 1960, em Salisbury, capital da então Rodésia e atual Zimbábwè; a MANU (Mozambique African National Union), fundada em Tanganica e localizada na atual Tanzânia em 1961; e a UNAMI (União Africana de Moçambique Independente) fundada em Niassalândia, atual Malauí em 1961 (História da Frelimo, [197-?], P. 5) Embora estes grupos tivessem como interesses comuns o anticolonialismo e a conquista da independência havia, entre eles, diferentes correntes políticas que caracterizavam seus anseios. Assim, o acordo de união não significou ausência de contradições dentro do novo grupo nacionalista. 
Em entrevista à Revista Tempo ${ }^{6}$, Marcelino dos Santos, membro do governo da Frelimo, comentou que a MANU e a UNAMI não emergiram como movimentos nacionalistas. Segundo ele, a MANU se reivindicava enquanto um movimento dos Macondes, designando-se, a princípio, de Maconde African Union e mais tarde Mozambique Maconde Union. No entanto, afirma que no período dos anos 60 era inaceitável que movimentos dedicados à proposta de libertação do colonialismo se definissem em termos de povos. Já a UDENAMO, dizia Marcelino dos Santos, era nacionalista, porém necessitava de maior afirmação quanto à sua proposta política. Tempo, set.1984, P 16-21.23).

As divergências políticas na Frelimo foram acirradas e entre os temas de discussões também estiveram: o tipo de guerra, exército, política e a emancipação feminina havendo, no decorrer da luta armada, a tentativa de alguns líderes proclamarem a independência unilateral de algumas áreas libertadas do colonialismo antes mesmo que a Frente obtivesse o controle da totalidade do território moçambicano. O assassinato de Eduardo Chivambo Mondlane, o primeiro presidente desta organização, em 3 de fevereiro de 1969, foi interpretado pela Frelimo como um reflexo de suas contradições internas. Samora Machel foi o presidente eleito em 1970 após a morte de Mondlane para a direção da Frelimo e do país independente.

Com o passar do tempo, a tendência marxista conquistou hegemonia na linha política da Frelimo. Segundo entrevista de Eduardo Mondlane feita em 1968 e publicada na Revista Tempo em 1984, a Frelimo foi se definindo como marxista e socialista no decorrer da luta armada. Confessou Mondlane que, em parte, isto foi uma contribuição de alguns militantes que já possuíam este conhecimento antes de participarem da luta armada e que a meta definida a partir da formação da Frelimo foi à luta contra o colonialismo e a necessidade de impor uma nova estrutura social, apesar de não se saber qual. Segundo ele, as mudanças ocorridas no movimento o autorizavam a concluir que, à altura do seu II $^{\circ}$ Congresso (1968), a Frente já era socialista e revolucionária, sendo a tendência naquela

\footnotetext{
${ }^{6}$ A Tempo foi criada em 1970 por intelectuais ligados à esquerda política de Portugal e desde então defensora de uma imprensa autônoma. Surgiu como uma alternativa à imprensa que existia, até aquele momento, marcada pela dura censura estabelecida no governo colonial fascista, mas as divergências na sua redação foram acirradas quando se tratou de aderir à política independentista da Frelimo e mesmo quando a coordenação já tinha sido ocupada em sua maioria por aqueles que eram a favor da independência e do novo governo, não faltaram divergências e conflitos com a política de informação estabelecida pela Frelimo. Essa revista constitui um campo de brechas que possibilita o contato com outros discursos sobre as mulheres no período. Se de um lado emerge em suas páginas uma imagem otimizada da mulher revolucionária, do outro, aparecem imagens das mulheres em seu cotidiano, manifestando resistências a esse discurso político, se apropriando e intervindo na sua formulação.
} 
ocasião muito mais direcionada ao socialismo do tipo marxista-leninista (Tempo, fev. 1984, P 18)

O movimento nacionalista em Moçambique se reivindicou como revolucionário. Este termo possui várias interpretações, mas, grosso modo, significa um movimento social que procura reconstruir uma nova ordem na sociedade, mudar seu corpo dirigente e sistema político. A proposta do movimento incluía a conquista da independência e a construção de um governo africano, descolonizado, popular, democrático e socialista. A prioridade do primeiro governo após a independência centrava-se na construção de uma nova sociedade, tarefa a ser assumida por toda população moçambicana, e dirigida pela vanguarda do processo revolucionário, a Frelimo (MACHIANA, 202, p.74).

\section{O Papel das Mulheres na Revolução de Moçambique}

A atuação das mulheres no processo revolucionário foi antecedida pela sua participação em movimentos contra o colonialismo. Antes mesmo do início da luta armada, camponesas cumpriram um papel estratégico na propaganda anticolonialista e essa experiência também foi vivenciada por grupos femininos das zonas urbanas, estudantes das cidades de Maputo e Xai-Xai que atuavam no Núcleo dos Estudantes Secundários Africanos de Moçambique (NESAM), de onde saíram lideranças que compuseram os primeiros quadros da Frelimo (ISAACMAM;STEFHAN,1984, p. 22)

O NESAM foi responsável por suscitar em um grupo de mulheres a vontade de se aliar à causa da independência. Porém, algumas delas não satisfeitas com a distribuição de panfletos chegaram ao manuseio de armas - foi o caso de Josina Machel, da província de Inhambane, que se inseriu na Frelimo em 1965. Sua atuação nesta organização lhe permitiu ocupar espaços superiores, como a chefia do Departamento de Relações Exteriores e Assuntos Sociais, prestando assistência, em especial, às causas das mulheres integrantes, ou não, da Frente de Libertação - quando uma de suas iniciativas foi a criação de orfanatos para os filhos das combatentes (ISAACMAM; STEFHAN, 1984, P 23).

Em decorrência de sua postura política foi indicada para participar do II $^{\circ}$ Congresso da Frelimo na condição de delegada, algo de importância singular, pois o evento abrigou uma das maiores crises da história da Frente, nele foram rediscutidas e definidas as diretrizes políticas do movimento e da luta de libertação nacional, inclusive o papel das mulheres na revolução. Josina Machel ofereceu, ainda, importantes contribuições através da sua participação na $\mathrm{II}^{\mathrm{a}}$ Conferência do Departamento de Defesa, "durante a 
qual expôs os obstáculos que se interpunham à integração cabal da mulher na revolução", apresentando algumas estratégias para a participação feminina, bem como sua emancipação (Tempo, abril. 1999, P. 19).

Josina Machel morreu em sete de abril de 1971 durante a Luta Armada e se tornou um exemplo memorável na história de Moçambique. Sua importante contribuição durante a guerra foi reconhecida por outras guerrilheiras e, segundo notícias da Tempo, foi delas a iniciativa de solicitar ao Comitê Central da Frente que o dia da morte dessa destacável líder se tornasse uma data histórica na vida do país. Em resposta à solicitação, a Frente decidiu eleger, em sua $5^{\text {a }}$ sessão realizada em dezembro de 1972, o 7 de abril como o dia nacional das mulheres moçambicanas (Tempo, abril. 1999, P. 19). Porém, Josina Machel não foi a única a combater durante a guerra de libertação nacional e nem foi esta a forma exclusiva de contribuição feminina, quer durante a luta armada, quer após a independência.

Para Isabel Casimiro, a iniciativa de formar um exército feminino partiu das próprias mulheres. Desde 1965, um grupo de mulheres camponesas havia solicitado treino militar à Frelimo com o intuito de defender as populações que se encontravam sob sua responsabilidade, tornando-se o primeiro Destacamento Feminino, apesar dos documentos e notícias mencionarem a sua criação apenas no ano de 1966, em uma reunião do Comitê Central. Isto demonstra que, ao menos em princípio, o motivo da reivindicação feminina para combater não se fundamentou em uma formação política, mas na necessidade que sentiram estas camponesas de se unirem em torno de uma causa coletiva para o seu bem e o de suas famílias (CASIMIRO, 2004. P 52-54).

A ausência da população masculina era muito comum no sul do país e isto se devia ao trabalho migratório dos maridos para as minas da África do Sul. Isto ocasionou a existência de povoados constituídos, em sua maioria, por velhos, crianças e mulheres que assumiam o papel de chefes de família. Eduardo Mondlane era um Changane, um dos povos da região sul de Moçambique. Em sua entrevista, ao ser questionado sobre as origens do seu interesse e dedicação pelos outros, confessou que desde criança tivera este aprendizado junto às mulheres da sua localidade, as quais eram as primeiras e únicas responsáveis pela garantia da sobrevivência. Embora na região norte o trabalho migratório não fosse incidente, a disposição das camponesas Macondes em defenderem seus territórios também denuncia a carência da presença masculina em suas famílias. De um modo geral, os movimentos autônomos de mulheres reunidos em torno de causas coletivas caracterizaram diferentes estruturas sociais do continente africano (Tempo, fev. 1984, P 19; CASIMIRO, 2004, P 173). 
A luta armada teve início em 1964, mas foi em outubro de 1966 que o Comitê Central da Frelimo passou a admitir mulheres em seu exército. A ampliação da luta armada para outras áreas e a necessidade de tornar este movimento autônomo no interior do país formaram, possivelmente, condições favoráveis a esta decisão. Para o alcance destes objetivos, a Frente determinou como imprescindível, o desenvolvimento da produção (agricultura, indústria artesanal e comércio) - um aspecto que já fazia parte das atividades desempenhadas pelas mulheres, pois, em boa parte da África subsaariana, a agricultura também era responsabilidade feminina e, em parte, o comércio ambulante e a produção artesanal. A novidade estava na decisão de que a participação das mulheres deveria ser garantida não somente nas tarefas de execução, mas na direção da luta armada em todos os escalões, inclusive nas reuniões do Comitê Central. O primeiro grupo de mulheres composto em sua maioria por moradoras de Cabo Delgado e Niassa - seria treinado em Nachingwea (Tanzânia), ocasião em que se formou um Destacamento Feminino (Voz da Revolução, agos.1978, P 3).

Entrevistas com guerrilheiras, publicadas na Tempo, possibilitam conhecer opiniões de algumas mulheres envolvidas nesta experiência. Filomena Likune, que alega ter sido colega de Josina Machel, na base de Beira a partir de 1968, foi uma das primeiras 25 mulheres Macondes a serem treinadas. Em sua entrevista, publicada em 1983, comentou ter havido pessoas contrárias à proposta de criar um segmento feminino do exército da Frelimo. Segundo Likune, duvidava-se da capacidade das mulheres para a guerra e achavase que a contribuição delas ao processo revolucionário deveria se restringir ao trabalho nas machambas (roças) e demais tarefas de apoio. Porém, "a direção do Partido decidiu que iríamos por experiência. Os resultados foram excelentes. Nenhuma de entre nós caiu durante os treinos, corríamos grandes distâncias sem problemas, conseguimos convencer sobre a nossa capacidade" (Tempo, mar. 1983, P 22).

Mônica Chitupila também foi integrante desta primeira turma de treinamento e na sua entrevista a revista Tempo mostrou o significado da inserção das mulheres no exército:

Fazíamos o trabalho de mobilização do povo, de produção agrícola para alimentar os combatentes. O nosso trabalho era importante porque havia pessoas que estavam convencidas de que a guerra seria de curta duração e então desesperavam. Tínhamos de encorajá-las. İamos fazendo estas tarefas, mas só depois do treino político em Nachingwea, a nossa ação se mostrou mais vigorosa. Em 1967 fiz parte do primeiro grupo que partiu do Niassa para treinar em Nachingwea juntamente com as mulheres de Cabo Delgado... cerca de 40 mulheres começaram os trabalhos na base (Tempo, abr. 1982, p. 23). 
Assumir a condição de guerrilheiras foi uma conquista das mulheres. Conforme comentário de Filomena Likuni tratou-se, em princípio, de uma experiência para observar se elas eram capazes de assumir tal tarefa e sendo proveitoso o desempenho em campo neste primeiro treino, a Frelimo oficializou o Destacamento Feminino. Likuni acrescentou ainda que as mulheres assumiam a tarefa de defesa, enquanto os homens dedicavam-se à empreitada do avanço da guerrilha - porém, houve aquelas que preferiram ocupar lugar nos combates junto aos homens. Para Josina Machel apesar de as guerrilheiras cumprirem um eficiente papel no campo militar, a maior contribuição delas se efetivou no campo político. Elas mobilizavam a população e, de modo especial às mulheres, visando despertar uma "compreensão política da guerra" e a adesão ao movimento. Essa atuação possibilitou ao Destacamento Feminino um substancial crescimento (Voz da Revolução, Jan. 1970, p. $1-13)$.

Muitas mulheres que não se inseriram no Destacamento Feminino continuaram a contribuir com a Revolução através de outras formas, como por exemplo: no transporte de material, na produção de alimentos para as (os) combatentes; como informantes, professoras ou enfermeiras. Nesse sentido, um caso memorável foi o de uma carregadora de equipamentos que, mesmo depois de ter constatado que seu filho atado ao seu corpo havia falecido, em decorrência de ter sido atingido por uma explosão durante o percurso, não deixou de prosseguir o seu caminho, cumprindo a missão de entregar o armamento que carregava a Frelimo (Tempo, Out. 1982, P 13).

As mulheres se tornaram necessárias à política da organização da Frelimo. Uma outra integrante deste primeiro grupo de treinamento militar feminino, através do seu depoimento na revista $V$ oz da Revolução, mostrou não ter sido fácil para as mulheres garantirem tal espaço. Apesar de não revelar o seu nome, a combatente Maconde se identificou como moradora de Namaua, do distrito de Mueda em Cabo Delgado e pertencente a uma família de sete irmãos. Em seu depoimento fez a seguinte consideração:

\footnotetext{
Quando nós mulheres começamos a trabalhar, houve forte oposição à nossa participação porque isso era contrário à nossa tradição. Iniciamos então uma grande campanha, explicando por que razão nós também devíamos combater, que a guerra desencadeada pela FRELIMO era uma luta popular, na qual todo o povo devia participar que nós mulheres éramos mesmo mais oprimidas que os homens, que tínhamos os mesmos direitos e a mesma determinação de combater. Insistimos para que nos fosse dado treino militar e armas (Voz da Revolução, mar. 1979, p. 28).
} 
Este testemunho revela a determinação que caracterizou a iniciativa e vontade das mulheres para o combate. Ocupar este novo papel social exigiu enfrentar reprovações de alguns membros da Frelimo e da população, de modo especial, dos homens. O comentário da depoente é incisivo. Foi preciso lançar uma campanha de convencimento e ainda tiveram que "temperar" seus argumentos com teimosia. Sua posição, em parte, já reflete o discurso desenvolvido na Frente por alguns líderes para justificar a necessidade de as mulheres participarem do processo revolucionário. Isto indica que a depoente já tinha sido contemplada com esta formação, pois foi convencionado na organização que trabalho militar e política eram inseparáveis. A fala da combatente ainda aponta para outra questão: o fato de que o grupo feminino também aderiu ao discurso da Frelimo porque, em parte, ele falava de suas dores, "somos mesmo mais oprimidas".

Em seu depoimento, a combatente ainda se referiu a experiências de opressão a que as mulheres eram submetidas durante a colonização. Sua família tinha uma pequena machamba (roça), embora raramente realizassem algum trabalho nessa terra em decorrência do trabalho forçado nas grandes plantações de algodão. Segundo ela, "os colonialistas portugueses eram muito maus, as mulheres não eram respeitadas e mesmo as casadas eram violadas na frente de seus maridos. Se estes reagissem ou se aquelas se recusassem, ambos eram barbaramente espancado, os colonialistas argumentavam que era uma honra para uma mulher negra ser desejada por um homem branco". A opressão das mulheres aumentou durante o período colonial não somente pelo fato de trabalharem mais e durante mais tempo ou por sofrerem exploração sexual, mas devido aos incentivos da legislação colonial e princípios do cristianismo que reforçaram a sua inferioridade (ISAACMAM;STEFHAN,1984, p. 22).

\section{O Discurso da Frelimo sobre a Mulher}

Através dos depoimentos das guerrilheiras, pode-se notar que a decisão de incluir as mulheres no processo revolucionário não foi resultado de um consenso. Esta experiência evocou rejeições e divergências políticas no interior da Frelimo e, sobretudo, serviu de impulso à construção e afirmação de um discurso sobre a mulher por esta organização.

O Comitê Central da Frente, ao informar sua decisão em relação às mulheres, declarou: "condenamos a tendência que existe entre muitos membros masculinos da Frelimo de excluir sistematicamente as mulheres das discussões de problemas relacionados 
à revolução e limitá-las à execução de tarefas" (7 de abril Dia Da Mulher Moçambicana,1968, doc). Esta advertência evidenciou um encorajamento aos membros desta organização para incluí-las em todos os níveis, mas também denuncia outros aspectos: primeiro, confirma ter havido resistências por parte de membros da Frelimo, o que já foi sinalizado no depoimento de uma das combatentes, citado anteriormente; segundo, essa resistência se relaciona com as contradições políticas que existiam dentro da organização; e, terceiro, ratifica que as mulheres exerceram pressão por participarem das decisões e, até mesmo, por assumirem outras tarefas diferentes daquelas que eram vistas como próprias do feminino. A iniciativa de ocuparem lugar no exército e de pensarem o processo revolucionário desencadeou uma onda de discussões dentro de Frelimo sobre a mulher e o seu papel na revolução (TÉTREAULT,1994, P 41-42).

A fundação do Destacamento Feminino suscitou reações agressivas em alguns membros da Frelimo. Segundo um breve comentário sobre o II $^{\circ}$ Congresso da Frente, realizado de 20 a 25 de julho de 1968, em uma publicação sobre a história da Frelimo, a resolução do Comitê Central de fundar o Destacamento Feminino provocou o descontentamento de alguns membros da organização, os quais tentaram investir contra as mulheres por acreditarem ser a família o seu lugar, ao cuidarem do trabalho nas suas machambas para os pais ou maridos. Alguns deles apelaram para a desmoralização das envolvidas na luta armada, inclusive levantaram calúnias contra elas. Entretanto, como diz o ditado popular, se juntou "a fome com a vontade de comer". Se as mulheres desejaram participar dos combates e mostraram notável desempenho, havia tendências teóricas na política da Frelimo, ao menos aquela que foi se tornando hegemônica, que legitimava sua participação. Quando Eduardo Chivambo Mondlane chamou atenção para o fato de que ninguém na Frente tinha pensado na possibilidade de as mulheres tornarem-se oficiais, ele anunciava uma discussão já tecida e algo inevitável de acontecer (HISTÓRIA DA FRELIMO [197-?]; VOZ DA REVOLUÇÃO, agos. 1978, P 3).

Em geral, o discurso de emancipação da mulher fez parte do discurso socialista. Porém, segundo Casimiro, a Frelimo foi o primeiro movimento socialista a incorporar a emancipação feminina à luta de libertação nacional (CASIMIRO, 2004, P 172). Sob influência do discurso socialista, mulheres se tornaram combatentes na Europa, Ásia, África e América Latina se envolvendo em processos de lutas político-militares de seus países, como nos casos da China, Timor Leste, Rússia, Albânia, Moçambique, Angola, Zimbábue, Argélia, Nicarágua, Cuba e San Salvador, dentre outros. Mas a inclusão das mulheres na luta armada pelo movimento de libertação nacional teria sido um socorro à 
falta de braços masculinos ou a atenção ao princípio de emancipação feminina presente no discurso socialista?

\section{A Discussão sobre Mulher e Socialismo: olhares do feminismo ocidental}

A relação entre mulheres e revolução tinha uma fundamentação teórica. Conforme Zuleica Alambert, o método de análise marxista preconizava o fim da opressão social por meio do proletariado unido a outros grupos sociais oprimidos, que, assumindo o controle do Estado, sobretudo da produção, estabeleceriam uma sociedade livre da exploração e estruturada em princípios de igualdade, independente de raça, sexo e religião. Ademais, a subordinação feminina foi vista como um resultado da exploração inerente à sociedade capitalista e relacionada ao problema da exploração. Esse tipo de análise refletia o pensamento de Marx e Engels, que preconizaram a subordinação feminina como resultado do surgimento da propriedade privada, tendo como conseqüência a restrição da mulher ao espaço doméstico para o cuidado e reprodução da mão-de-obra operária, exercendo, dessa forma, uma função acessória na produção do sistema capitalista. Desse modo, a subordinação feminina era uma questão social somente resolvida com o socialismo (ALAMBERT,1986.P21-48;KOLONTAI,1982, P 1-101).

Apesar dessa discussão, algumas experiências socialistas indicaram não ter havido mudanças significativas para a condição social das mulheres. Maxine Molineux afirma que após algumas décadas do socialismo, as análises sobre a condição feminina na sociedade demonstraram a persistência da desigualdade de gênero e, em alguns aspectos, uma situação pior que no capitalismo, além disso, indicavam desesperança em relação ao compromisso dos governos socialistas com a emancipação feminina. Para Molineux, esta imagem negativa do socialismo ainda se tornou mais agravante ao considerar a ausência de democracia popular e dessa igualdade de gênero no poder político de Estado. Ao analisar a experiência da revolução sandinista (Nicarágua) ela constatou não ter sido diferente. Após a conquista da independência, na qual homens e mulheres combateram juntos, elas não alcançaram sua emancipação, embora houvesse promessas de uma experiência socialista mais democrática, independente e moderna do que aquelas estabelecidas em outros países. Essas advertências ganharam muita atenção devido ao contexto em que o movimento revolucionário eclodiu, posterior ao surgimento de uma onda de organizações femininas em todo o mundo (anos 60) além da disposição crítica de seus líderes à ortodoxia marxista presente em outros governos (MOLINEUX, 1984. P 179-196). 
A Frente Sandinista tinha definido como principais estratégias de emancipação para as mulheres: ampliar o seu acesso ao trabalho assalariado; socializar o trabalho doméstico e o cuidado com os filhos e filhas; igualdade legal; proteção à mãe e à família; mobilizar as mulheres para atividades políticas; eliminar a prostituição e outros vícios sociais e incentivar a um maior controle reprodutivo. Contudo, após certo tempo de governo, esses compromissos foram adiados (MOLINEUX, 1984. P 188)

Para Molineux, estas medidas eram, em sua natureza, insuficientes para gerarem uma emancipação completa. Elas expressavam uma visão limitada dos interesses femininos e um número muito inferior de mulheres conseguiu ter acesso ao trabalho assalariado e à socialização do cuidado da prole, atingindo de uma forma mais ampla demais benefícios de bem-estar social e algumas reformas legais - ainda assim a fratura entre a intenção e ação foi notável. Molineux, ao avaliar o porquê dessa situação, propôs três explicações: a limitação econômica, que impediu o estado de executar alguns dos projetos voltados para esse interesse; fatores políticos e a própria concepção sandinista de libertação. Concluiu que a natureza da proposta de emancipação desse governo possuía muito mais um caráter reformista do que revolucionário (MOLINEUX, 1984. P 189-191).

$\mathrm{Na}$ interpretação de Andrea Nye, a condição das mulheres no socialismo foi marcada por retrocessos. Para ela, a teoria socialista incluiu de forma superficial a libertação das mulheres e isto se refletiu no pensamento de seus seguidores. Os adeptos do pensamento de Saint Simon, ao mesmo tempo em que eram a favor da emancipação das mulheres, retrucavam a qualquer iniciativa de formar organizações femininas para tratar de sua situação específica, alegando que com a abolição da propriedade privada as diferenças de poder entre marido e mulher estariam resolvidas. Para Nye o fato da emancipação das mulheres não ter sido alcançada com o socialismo teria sido um resultado da inadequação do marxismo para o tratamento da desigualdade de gênero, uma vez, que seus princípios analíticos não incluía o trabalho doméstico na esfera de produção (NYE, 1995. P 51-76).

Mas outras reflexões indicam caminhos diferentes na forma de pensar as relações de gênero e marxismo. O casal Pat and Hugs Armstrong concorda que a análise marxista centrou-se no aspecto da luta de classes e marginalizou a questão de gênero, porém sugeriu que isto não significava um atestado de inutilidade desse método para pensar as relações de gênero, havendo uma necessidade de se repensar o marxismo para um melhor uso de sua teoria. Os Armstrong apontaram que existem diferentes formas de análise no marxismo, distinguindo a tendência determinista, que tende ao dogmatismo, daquela que leva em conta a influência das subjetividades (HAMILTON; BARRET, 1986. 208-237). 
Para o casal, o trabalho doméstico deve ser visto como parte integrante da produção. $\mathrm{Na}$ tentativa de adequar uma leitura de gênero em uma teoria que priorizava a classe, feministas socialistas se empenharam em discutir o trabalho doméstico e isso contribuiu para tornar esse trabalho visível, além de valorizá-lo. No entanto, suas discussões tenderam a marginalizar o trabalho doméstico do campo da produção - em vez de acentuar a interdependência existente entre ambos. É através desse tipo de trabalho que o operariado é cercado de cuidados necessários para produzir, além de ser um espaço de reprodução da mão-de-obra a ser absorvida pelo mercado; tudo isso é realizado sem gerar ônus ao empregador (HARDING, 1993. P 7-32).

É com base nesta reflexão que os Armstrong sugeriram, entre a produção e a reprodução existe uma relação de interdependência. A produção doméstica é um suporte para o funcionamento do sistema capitalista, desse modo, ao contrário de considerar a teoria marxista como um método impróprio para a análise de gênero, ela deve ser utilizada para analisar o processo de exclusão e subordinação da mulher pelo homem e pelo Estado do sistema capitalista. Seu argumento possibilita pensar no trabalho doméstico enquanto trabalho assalariado e em novas relações do Estado para com o espaço domiciliar - uma responsabilidade relegada ao público feminino e legalmente sob o poder do operariado masculino, embora a condição de chefes de família fosse uma realidade assumida também por mulheres. A proposta dos Armstrong ainda resolve o problema da dupla jornada de trabalho das mulheres. Contudo, essa proposta guarda o perigo de incentivar a restrição do feminino ao espaço doméstico, ocasionando um retrocesso nas conquistas até então estabelecidas.

A saída massiva da mulher para o mercado não implicou em negociação das tarefas domésticas com o seu cônjuge, mas em um considerável aumento de suas tarefas. Além do trabalho doméstico não ser reconhecido financeiramente, o salário recebido pelo trabalho realizado na empresa era inferior ao recebido pelos homens. Contudo, proporcionou uma rediscussão das relações de gênero e do lugar da mulher na sociedade, assim como incitou mudanças concretas na forma de o grupo feminino pensar sobre si e ser reconhecido na sociedade, entre outros aspectos. Outra questão a ser considerada é que valores de raízes culturais estão envolvidos na geração das desigualdades entre homens e mulheres que ultrapassam esta engrenagem econômica, ou seja, não basta ter independência econômica para que as mulheres sejam tratadas como iguais na sociedade. 


\section{A Discussão sobre Mulher e Socialismo: o olhar da Frelimo}

No caso da Frelimo, a decisão política de que era preciso pensar na libertação das mulheres durante a luta de libertação nacional deu margem a acirrados debates. De modo especial no II ${ }^{\circ}$ Congresso da Frente (1968) e na reunião do seu Comitê Central, em 1972. Alguns discursos de Samora Machel, publicados em livros de formação política e artigos da Tempo, permitiram obter uma noção da natureza deste debate.

Um destes discursos, publicado na íntegra, foi proferido por Machel na abertura da primeira Conferência das Mulheres Moçambicanas. Esse evento foi convocado pela Frente de Libertação, em 1973, e realizou-se na Tanzânia. O objetivo desta Conferência foi discutir a condição social das mulheres moçambicanas e pensar estratégias para a sua emancipação. Nessa Conferência estiveram reunidas mulheres de diferentes Províncias, profissões, condições sociais, idades e "etnias" - tanto do norte quanto do sul de Moçambique, incluindo camponesas, professoras, enfermeiras, militares, estudantes, solteiras e casadas (MACHEL, 1979. P 13-44).

Em seu discurso, Machel revelou alguns aspectos do debate que vinha ocorrendo sobre a mulher na Frelimo. Iniciou sua fala com dois questionamentos que, possivelmente, devem ter aquecido a discussão entre seus membros. "Por que preocuparmos-nos com a emancipação da mulher? Qual a razão de convocarmos agora esta Conferência?’. Entre os membros da Frelimo, as opiniões variavam a esse respeito. Segundo Machel, para uns, a prioridade naquele momento deveria ser a destruição das estruturas do colonialismo, sendo a emancipação das mulheres uma tarefa secundária e algo que deveria ser tratado após a independência e quando o país pudesse contar com uma base econômica, social e educacional sólida. $\mathrm{Na}$ visão de outros, investir na emancipação das mulheres exigia um sistema educacional estruturado, pois isso implicava não somente em alfabetizá-las, mas conscientizá-las das novas concepções relativas à identidade da mulher revolucionária, uma vez que a maioria ainda se encontrava muito "apegada à tradição" (MACHEL, 1979. P 1618).

Alguns, ainda utilizando-se dos Estatutos do Movimento. Acreditavam ser necessário respeitar as práticas culturais locais, pois seu combate poderia ocasionar a perda de apoio das populações ao movimento de libertação nacional. Ainda consideravam que não havia necessidade de investir nessa tarefa porque as mulheres não estavam sensibilizadas para isso. Tratava-se de algo artificial, uma invenção de alguns líderes da 
Frelimo imposta às mulheres. Depois de tornar pública essa diversidade de opiniões, Machel também comunicou a resolução desse debate.

\begin{abstract}
A libertação da mulher é uma necessidade fundamental da Revolução uma garantia de sua continuidade, uma condição de seu triunfo. A Revolução tem por objetivo essencial a destruição do sistema de exploração, a construção de uma nova sociedade libertadora das potencialidades do ser humano e que o reconcilia com o trabalho, com a natureza. É dentro deste contexto que surge a questão da emancipação da mulher. Não se pode liquidar só uma parte da opressão (...) Como fazer então a Revolução sem mobilizar a mulher? Se mais da metade do povo explorado e oprimido é constituído por mulheres, como deixálas à margem da luta? A Revolução para ser feita necessita mobilizar todos os explorados e oprimidos, por conseqüência, as mulheres também (MACHEL,1979, p.18).
\end{abstract}

A Frelimo definiu a libertação da mulher como um compromisso inadiável. De uma forma geral, o princípio da emancipação da mulher esteve presente nos discursos dos governos socialistas em todo o mundo, mas, ao invés de adiar o compromisso da emancipação para uma fase posterior da revolução, a Frente considerou que ele deveria ser simultâneo ao da libertação nacional e estruturação do socialismo e, além disso, afirmou o envolvimento das mulheres como uma necessidade vital do processo revolucionário. Conforme o pensamento mais geral, a Frelimo também considerou que a exploração da mulher era parte integrante da exploração de classe presente na sociedade. Machel, em outro trecho do seu discurso, na abertura da Conferência das Mulheres Moçambicanas, evidenciou esta tendência:

\begin{abstract}
A exploração da Mulher é um aspecto do sistema geral de exploração do homem pelo homem. E esta exploração que cria condições de alienação da mulher, a reduz à passividade e a exclui da esfera da tomada de decisões da sociedade. Assim, as contradições antagônicas que existem são entre a mulher e a ordem social exploradora. Estas contradições são as mesmas que opõem a totalidade das massas exploradoras do nosso país e do mundo às classes exploradoras (...) Só a Revolução é capaz de resolver definitivamente esta contradição porque só ela encarna os interesses das massas exploradoras, mobiliza, organiza e une para o combate, só ela é capaz de destruir a ordem social antiga. É a Revolução que instala no poder as massas exploradas, as massas que viviam oprimidas e eram forçadas à passividade (MACHEL, 1979, p. 18).
\end{abstract}

Apesar dessa visão economicista comum que se faz transparecer no discurso de Machel, a opressão das mulheres na sociedade moçambicana apresentava aspectos singulares. No pensamento socialista mais geral, essa opressão resultava do encarceramento das mulheres no espaço domiciliar, considerado pelas feministas como um grande obstáculo à sua inserção no campo da produção. No entanto, em Moçambique, elas 
eram peças centrais na produção, cabendo-lhes o trabalho na agricultura e no comércio ambulante a fim de proverem suas famílias.

Assim como em outros países da África, a agricultura se destacou como uma das principais fontes da economia. Durante a colonização, as mulheres foram marginalizadas das relações de produção do Estado, além do trabalho ser um atributo legalmente da população masculina, predominou nesse período, uma agricultura de modelo capitalista voltada para o mercado exterior e de mão-de-obra assalariada. Entretanto, a atuação feminina na produção familiar se manteve. Após a independência, a Frelimo tentou destruir a proeminência da produção familiar visando o fortalecimento de uma economia nacional com bases em uma agricultura industrializada e voltada para o mercado externo, mas, ao contrário da administração colonial, o seu governo procurou incentivar as mulheres a adquirirem conhecimento técnico para continuarem fazendo parte da produção. Em boa parte das sociedades africanas, o segmento feminino desempenha um papel fundamental na economia, apesar de o seu trabalho nem sempre resultar em salário (TEMPO, 1984. Out, p. 19; MORA; PEREYRA, 1999, p. 69-107).

A forma de organização social tradicional ${ }^{7}$ permitiu às mulheres ocuparem o papel de produtoras. Em boa parte do continente africano, a organização das sociedades foi fortemente influenciada pelas relações de parentesco que tem como base o sistema de linhagens. Trata-se de um sistema variado e com um nível de predominância diferenciado nos espaços urbanos e rurais, porém, podem apresentar alguns aspectos comuns. Baseia-se na descendência unilinear, isto é, na pertença de um indivíduo ao grupo de descendência (linhagem) e se estabelece por filiação transmitida exclusivamente através do pai ou da mãe. Nesse sentido, a teoria antropológica distingue entre patrilinhagens (linhagens formadas por descendência masculina) e matrilinhagens (linhagens formadas por descendência feminina). Nos sistemas patrilineares, uma mulher pertence à linhagem do seu pai, mas seus filhos pertencem à linhagem do seu esposo. Contrariamente, nos sistemas matrilineares um homem pertence à linhagem da sua mãe e seus filhos pertencem à linhagem da sua esposa (GEFRAY，2000，p. 19-40; LOFORTE，2000，109-136; PISCITELLI，1998，305-321; LOVEJOY, 2002, 29-51).

No período em estudo da história de Moçambique estas duas formas de sistemas de linhagens mostraram-se influentes. Quanto a sua distribuição pode se identificar, ao norte

\footnotetext{
${ }^{7}$ A palavra tradicional aparece de forma freqüente nas fontes em contraposição à sociedade socialista que a Frelimo tentou estruturar. É nesse sentido que o termo tradicional é utilizado nessa dissertação, não sendo entendido como algo estático no tempo, mas como um conjunto de práticas sociais com base no costume dos povos locais.
} 
predominância da descendência matrilinear, incluindo as Províncias de Niassa, Cabo Delgado e Nampula; ao sul nas Províncias de Gaza, Maputo e Inhambane predominava o sistema patrilinear; e à região central do país, envolvendo as Províncias de Zambézia, Tete, Sofala e Manica, o encontro dessas duas formas de linhagens.

Nas sociedades de predominância patrilinear as mulheres geravam valor e elas próprias eram os bens de troca. Embora com nomes e formas variadas as práticas culturais do casamento tradicional e da poliginia foram comuns nos dez primeiros anos após a independência e ainda persistem até os dias atuais. Por lobolo se compreende um benefício que pela lei consuetudinária a família da noiva tem direito, por ocasião do casamento, a uma compensação que pode ser paga em cabeças de gado, dinheiro, ou por outros objetos considerados de valor para essa cerimônia. Era também através do casamento que os descendentes de um mesmo ancestral passavam a ter direito a terra, incluindo as árvores, frutos, água, cereais e produtos agricultáveis (LOFORTE, 2000, p 128-131; MACHEL, 1979. P 22).

Pelo costume, no sistema patrilinear as mulheres tinham a obrigação de se deslocarem para a casa do marido. Elas recebiam um terreno onde deveriam se dedicar ao cultivo agrícola, podendo o esposo multiplicar esses bens através do aumento do número de posses da suas esposas. Em caso de viuvez, as mulheres passavam a ser esposas do irmão do falecido, a recusa trazia sansões como a perda de toda herança e até o direito aos filhos. Para a Frelimo, as mulheres de famílias poligínias eram exploradas pelo marido, uma vez que eles acumulavam riquezas com o trabalho gratuito de suas esposas. Embora na perspectiva do Estado moderno ocidentalizado esse papel social e econômico ainda fosse reconhecido como pertencente ao mundo doméstico, não se pode negar que o ambiente domiciliar nesse contexto africano superasse o caráter de privado, vindo a tornar-se também público.

A Frelimo considerou que a emancipação feminina ${ }^{8}$ se efetivaria mediante o envolvimento das mulheres na estruturação da revolução. Todavia, em contradição ao pensamento de alguns socialistas, admitiu a necessidade de uma organização feminina que atuasse na mobilização das mulheres nesse novo processo, discutisse estratégias e lançasse mão de ações necessárias à concretização da sua emancipação - uma atitude singular em relação a outras experiências socialistas que julgavam desnecessária a formação de uma

${ }^{8}$ A Frelimo concebia que a emancipação feminina e o processo revolucionário eram coisas indissociáveis. Apesar de reconhecer a existência da dominação masculina, Machel, em seus discursos, enfatizou que opressão feminina era uma conseqüência direta da estrutura do sistema econômico, sendo imprescindível para a emancipação das mulheres, o seu engajamento na revolução socialista. 
organização específica para tratar da questão das mulheres, uma vez que a questão de classe era considerada hegemônica. A Frelimo antes mesmo da independência convocou uma Conferência das Mulheres para discutir estratégias de emancipação feminina e, nessa mesma ocasião, fundou a Organização das Mulheres Moçambinas, a OMM, em 1973 (ALAMBERT, 1986. P 1-128)

Entretanto, a OMM foi definida como uma organização de base da Frelimo e devia seguir suas diretrizes políticas. Sua função principal era trabalhar pela emancipação feminina e isto consistia em envolver as mulheres nas tarefas da Revolução e fazer com que elas conhecessem a linha política do futuro Partido e Governo. Outra função considerada primordial foi o internacionalismo, isto é, a sua articulação com outras organizações de mulheres no mundo. Portanto, não se tratava de uma organização autônoma. Para Casimiro, a OMM foi criada sem o consentimento de algumas guerrilheiras por estarem convencidas de que o Destacamento já vinha cumprindo um papel de mobilização - não somente daquelas envolvidas no exército da Frelimo, como também daquelas pertencentes à população. Apesar de a Frelimo ter nomeado o Destacamento Feminino como um núcleo da OMM, as mulheres que passaram pela experiência da luta armada não assumiram o controle dessa organização (MACHEL, 1979, P 34; CASIMIRO, 2004, P 175).

Nas notícias da Tempo, líderes da OMM reconheceram em sua II ${ }^{a}$ Conferência que a incapacidade da direção integrar os quadros do Destacamento Feminino na organização ocasionou sua inoperância (Doc. II CONFERÊNCIA DA OMM; Tempo, 1976,dez. P 2627).Filomena Likune, uma das primeiras guerrilheiras do Destacamento Feminino, em sua entrevista a Tempo, fez referência a mulheres que tiveram uma atuação significativa no passado, mas que deixaram de participar após a criação da OMM (TEMPO, 1983, abr. P 64). Na opinião de Casimiro a criação da OMM foi uma forma da Frelimo exercer controle sobre o espírito de liderança das mulheres. De fato, não é nenhum exagero pensar na possibilidade dessa organização ter atuado como um freio às ações que as líderes do Destacamento Feminino vinham desenvolvendo (CASIMIRO, 2004. P 175-176).

A vitória da independência de Moçambique foi solenemente proclamada na noite de 25 de Junho de 1975. Depois de dez anos de guerra, o país passava à condição de República Popular, sendo esta conquista motivo de muitas comemorações entre a Frelimo e a população, de modo geral. Margarida Cardoso, em seu documentário sobre a atuação do cinema no país - no qual se encontram expressivas imagens do jornal cinematográfico, Kuxa Kanema - guardou os primeiros instantes vivenciados pela população moçambicana 
a partir da independência. Através deste documentário, ainda é possível escutar trechos do discurso emocionado do presidente Samora Machel em homenagem à vitória conquistada: "quando esta bandeira subiu à meia noite de 25 de Junho chorávamos de alegria, por quê? (...) Porque estávamos livres! É ou não é? A coisa mais bela que há na vida de um homem é viver independente, pode não ter comida, pode não ter roupa, mas é livre". A Tempo também demonstrou a importância e o significado desse fato histórico através de suas reportagens e imagens fotográficas sobre a primeira visita presidencial às Províncias do país expressando nessas notícias uma fervorosa disposição e cumplicidade na alegria da vitória manifestada pela população em seu encontro com a Frelimo.

Entre as políticas sociais do governo pós-independência, a emancipação das mulheres se destacou como uma das prioridades. Essa iniciativa resultou do fato da Frelimo desde a sua formação (1962) ter definido a emancipação feminina como uma de suas diretrizes políticas, mas também, da atuação que as mulheres tiveram durante o período da luta de libertação nacional, não se tratando simplesmente de uma política de concessão do novo governo.

\section{Referências Bibliográficas}

1. ALAMBERT, Zuleica. Feminismo: O ponto de vista Marxista. São Paulo: Nobel, 1986.

2. ARAGUEN, Marysa Navarro. Miranda nueva-problemas viejos. In: LUNA, Lola (org). Mujeres y sociedad-nuevos enfoques teóricos y metodológicos. Barcelona: Universidade de Barcelona, 1991 pp 101-109.

3. ARMSTRONG, Pat and Hugs. Beyond sexless class and classless sex: Towards Feminist Marxism. In: HAMILTON, Roberta e BARRET, Michele (eds). The politics of diversity, feminism, Marxism and nationalism. London: Verso, 1986. pp 208-237.

4. CABRITA MATEUS, Dalila. A Luta pela independência: a formação das elites fundadoras da Frelimo, MPLA, PAIGC. Portugal: Inquérito, 1999.

5. CASIMIRO, Isabel. Paz na terra, guerra em casa: feminismo e organizações de mulheres em Moçambique. Maputo: Promédia, 2004.

6. COMITINI, Carlos. A África arde: lutas dos povos africanos pela liberdade. Rio de Janeiro: Codecri, 1980. p. 18-119.

7. CORREIA, Sônia; HOMEM, Eduardo. Moçambique primeiras machambas. Rio de Janeiro: Margem, 1977. 
8. DOCUMENTO 7 de Abril dia da mulher moçambicana, 1968.

9. DOCUMENTO da $2^{\mathrm{a}}$ conferência da organização da mulher moçambicana. Maputo, 10 a 17 de novembro de 1976.

10. GEFFRAY, Christian. Nem pai nem mãe: crítica do parentesco: o caso macua. Lisboa:Ndjira, 2000. p. 19-40.

11. HISTÓRIA DA FRELIMO. Relatório do comitê central da Frelimo. Maputo: Departamento de Trabalho Ideológico Frelimo, [197-?]. p. 13-22. (Coleção Conhecer, v. 4).

12. HERNANDEZ, Leila Maria Gonçalves Leite. A África na sala de aula: visita a história contemporânea. São Paulo: Selo negro, 2005. p.131-155

13. ISAACMAM, Bárbara e STEFHAN, June. A mulher moçambicana no processo de libertação. Maputo: Instituto Nacional do Livro e do Disco, 1984.

14. LOFORTE, Ana Maria. Gênero e poder: entre os Tsongas de Moçambique. Maputo: PROMÉDIA, 2000 p. 109-136.

15. LOVEJOY, Paul. A Escravidão na África: uma história de suas transformações. Rio de Janeiro: Civilização Brasileira, 2002. p 29-51

16. MACHEL, Samora. et al. A Libertação da mulher. São Paulo: Parma, 1979. p. 1344. (Coleção bases n. 15)

17. MACHIANA, Emídio. A Revista tempo e a revolução Moçambicana: da mobilização popular ao problema da crítica na informação. 1974-1977. Maputo: Promédia, 2002. (coleção identidades).

18. MORA, Luis Maria; PEREYRA, Verónica. Mujeres y solidaridad:.estrategias de supervivencia em el África subsahariana. Madrid: Instituto Universitário Desarrollo y Coperación, 1999 p. 69-107.

19. PISCITELLI, Adriana. Nas fronteiras do natural: gênero e parentesco. Estudos feministas. v. 6 n. 2, P 305-321,1998.

20. REVISTA TEMPO (1975-1985) 